\title{
EFFECT OF HYOSCINE BUTYLBROMIDE (BUSCOPAN) AS CERVICAL SPASMOLYTIC AGENT IN LABOUR
}

\author{
Sree Ramya Narappagari ${ }^{1}$, Himabindu² \\ ${ }_{1}^{1}$ Postgraduate, Department of Obstetrics and Gynaecology, RGGWCH, Puducherry. \\ ${ }^{2}$ Associate Professor, Department of Obstetrics and Gynaecology, IGMCRI, Puducherry.
}

\section{ABSTRACT}

\section{BACKGROUND}

Progression of labour requires effective cervical dilatation and effacement in addition to good uterine contractions. A commonly available spasmolytic namely Buscopan (Hyoscine-N-butylbromide, HBB) is known to inhibit smooth muscle contraction in the cervix and thus enhance cervical dilatation in labour. In the present study, outcome of labour after usage of Hyoscine is studied.

Setting- During the study period of 1 year, 200 full-term pregnant women satisfying the inclusion and exclusion criteria in active phase of labour ( $>3-4 \mathrm{~cm}$ of cervical dilatation) admitted in RGGWCH, Pondicherry who gave informed consent were taken into the study.

\section{MATERIALS AND METHODS}

For every patient in the study group, age and parity matched next patient was taken as control for that case. In the study group, Buscopan $20 \mathrm{mg}$ slowly intravenously and in control group $10 \mathrm{~mL}$ normal saline was given. Duration of active phase of labour and percentage change of pain score after 2 hours in both the groups is noted. Statistical analysis was done by using SPSS software version 19.0. $P$ value of $<0.05$ is taken as significant.

\section{RESULTS}

Among primigravidae, the mean duration of active phase of labour in Buscopan group and control group is found to be 114 and 182 minutes respectively ( $p$ value $<0.002$ highly significant). Among multigravidae, the duration was found to be 89 minutes and 113 minutes respectively in Buscopan group and control group (statistically insignificant with p value of 0.27). No significant difference was observed in the duration of second and third stage of labour, mode of delivery, birth weight, Apgar score and colour of the liquor in both the groups. A percentage change of pain by $17 \%$ was observed in Buscopan group which was statistically significant. Transient side effects like maternal and foetal tachycardia were observed in few cases. But no adverse effects on the mother and the foetus were observed in these cases.

\section{CONCLUSION}

Effective shortening of the duration of labour and pain relief can be achieved without any significant detrimental effects on the mother or the foetus.

\section{KEYWORDS}

Cervical Dilatation, Active Phase of Labour, Buscopan, Pain Score.

HOW TO CITE THIS ARTICLE: Narappagari SR, Himabindu. Effect of hyoscine butylbromide (Buscopan) as cervical spasmolytic agent in labour. J. Evolution Med. Dent. Sci. 2016;5(90):6670-6674, DOI: 10.14260/Jemds/2016/1509

\section{BACKGROUND}

Labour is a physiological process characterised by progressive increase in the frequency, intensity and duration of uterine contractions associated with effacement and dilatation of cervix with descent of foetus through the birth canal. ${ }^{1}$ In the process of labour, one's major concern centres on the duration of labour. It is observed quite often that in spite of good uterine contractions and descent of the presenting part, cervix fails to dilate. This condition is called functional cervical dystocia. Cervical dilatation is the result of all the driving forces of uterine contractions acting against passive tissue resistance and it serves to reflect the process of labour.

Financial or Other, Competing Interest: None.

Submission 27-09-2016, Peer Review 28-10-2016,

Acceptance 04-11-2016, Published 09-11-2016.

Corresponding Author:

Sree Ramya Narrappagari,

12/643, Kota Street,

Proddatur-516360,

Andhra Pradesh.

E-mail: ramyanarreddy@gmail.com

DOI: $10.14260 /$ jemds $/ 2016 / 1509$

\section{(c) $($ ) $\odot$}

The use of smooth muscle relaxants reduces the resistance offered by cervix. Administration of smooth muscle relaxants to augment cervical dilatation and labour progress is well accepted.

A commonly available spasmolytic namely Buscopan (Hyoscine-N-butylbromide, HBB) is known to inhibit smooth muscle contraction in the cervix. Buscopan is a quaternary ammonium compound. It is a derivative of hyoscine, which is extracted from the leaves of the Duboisia tree. HBB acts by inhibiting the cholinergic transmission in the abdominopelvic parasympathetic ganglion, thus relieving spasm of the smooth muscles of GIT, biliary and genitourinary organs especially the cervicouterine plexus, thus aiding cervical dilatation. In addition, Buscopan also has an analgesic effect. Hence, Buscopan is preferably given after onset of active phase. ${ }^{2}$

Obstetricians from various parts of the world have studied the efficacy of Buscopan on cervical dilatation and found that its efficacy is comparable to other drugs for cervical dilatation.

The results are conflicting; some of the studies demonstrated the efficacy in augmenting labour,3-6 while others showed no effect, 2,7 Moreover, the differences between primi and multigravidae are not clearly defined. Very few 
studies have been carried out to evaluate the role of Buscopan as an analgesic. ${ }^{8}$

The present study was conducted in order to determine whether Buscopan shortens the first stage of labour, to evaluate its efficacy as analgesic and to study the incidence of maternal and neonatal complications, following its usage.

\section{MATERIALS AND METHODS}

A prospective comparative study was undertaken in RGGWCH Pondicherry, from December 2014 to November 2015. Ethical clearance (IEC) was obtained from the institute's ethical committee prior to the study. Fullterm pregnant women satisfying the inclusion and exclusion criteria admitted in active labour in RGGWCH, Pondicherry during the study period who gave informed consent were taken in the study. For every patient in the study group, age and parity matched next patient was taken as control for that case.

\section{Inclusion Criteria}

Women with

1. Normal singleton pregnancy.

2. Pregnancy at 37-41 weeks.

3. Vertex presentation.

4. Active labour.

\section{Exclusion Criteria}

Women with

1. Previous uterine scar.

2. Malpresentation.

3. Cephalopelvic disproportion.

4. Antepartum haemorrhage.

5. Twin pregnancy.

In both groups, active management of labour was carried out in the form of amniotomy once patient entered active phase of labour $(>3 \mathrm{~cm})$. Oxytocin infusion was used if uterine contractions were not effective. Injection Tramadol $50 \mathrm{mg}$ IM was given for all patients uniformly at recruitment.

\section{In Group-A (Buscopan)}

Hyoscine butylbromide $20 \mathrm{mg}$ diluted with distilled water up to $10 \mathrm{cc}$ was given slowly intravenously.

\section{In Group-B (Control)}

$10 \mathrm{~mL}$ normal saline was given at the same rate intravenously. Participants received the contents as a single dose, intravenously when they were assessed and recruited into the study. The progress of the participants was closely documented by the principal investigator till delivery. The conduct of labour and delivery for both the cases and control groups was in accordance with labour ward protocol of the institute.

Women in both the groups were asked to mark pain they felt at the point of recruitment into the study and 2 hours later using visual analogue scale. Per vaginal examination was repeated at 4 hours and 8 hours duration after entry into the study. Partographic evaluation for the rate of cervical dilatation in the first stage and followup for the duration of the second stage, third stage of labour, caesarean section rate, assessment of blood loss and APGAR score for the neonates were noted. Intervention through instrumentation or caesarean section was by the usual obstetric determinants.
Based on the VAS, percentage change in pain from baseline is recorded. Percentage pain relief is the difference in pain score just before treatment and pain score two hours later.

The primary outcomes studied were the rate of cervical dilatation, duration of first stage and percentage change in pain. The secondary outcome measures compared were the duration of second stage of labour, mode of delivery, neonatal outcome and any side effects of the drug.

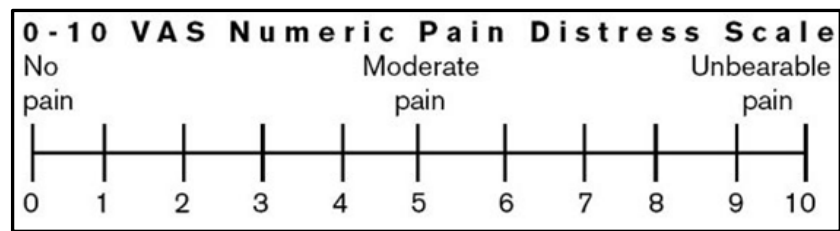

Figure 1. Visual Analogue Scale used in the Present Study

\section{RESULTS}

The observations of the study were analysed. Under both the groups, there were uniformity of cases with regard to mean age, period of gestation and parity.

\begin{tabular}{|c|c|c|}
\hline Parameters & $\begin{array}{c}\text { Buscopan } \\
\text { Group }\end{array}$ & $\begin{array}{c}\text { Control } \\
\text { Group }\end{array}$ \\
\hline Age & $24.62 \pm 3.53$ & $24.67 \pm 3.91$ \\
\hline Period of gestation & $39.1 \pm 2.1$ & $39.1 \pm 0.89$ \\
\hline Primigravida & 60 & 59 \\
\hline Multigravida & 40 & 41 \\
\hline $\begin{array}{c}\text { Oxytocin } \\
\text { acceleration }\end{array}$ & $24 \%$ & $20 \%$ \\
\hline
\end{tabular}

Among primigravidae who received Buscopan, the mean duration of active phase of labour was 114 minutes which is very less compared to the duration in control group of 182 minutes. This decrease in duration is found to be highly statistically significant with $\mathrm{p}$ value $<0.002$. The rate of cervical dilatation among primigravidae was $4.7 \mathrm{~cm} /$ hour and $3 \mathrm{~cm} /$ hour in Buscopan and control groups respectively.

The mean duration of active phase of labour in multigravidae was found to be 89 minutes and 113 minutes respectively in Buscopan group and control group. However, this decrease in the duration was found to be statistically insignificant with $\mathrm{p}$ value of 0.27 . The rate of cervical dilatation in these women was calculated to be $5.3 \mathrm{~cm} /$ hour and 4 $\mathrm{cm} /$ hour which is statistically just significant.

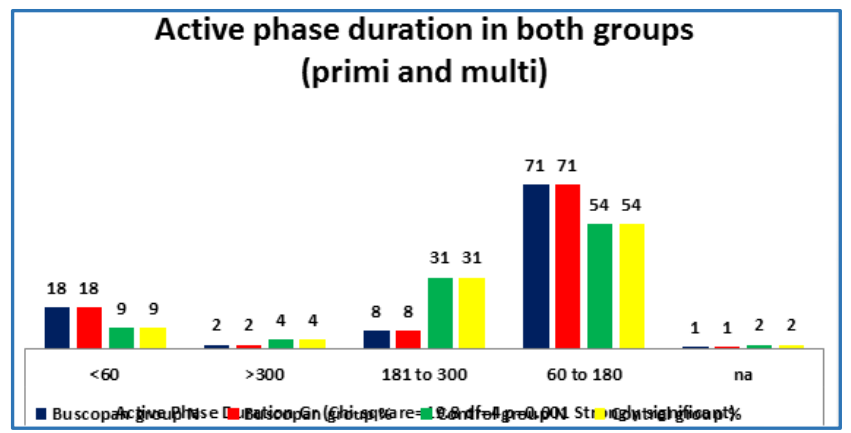




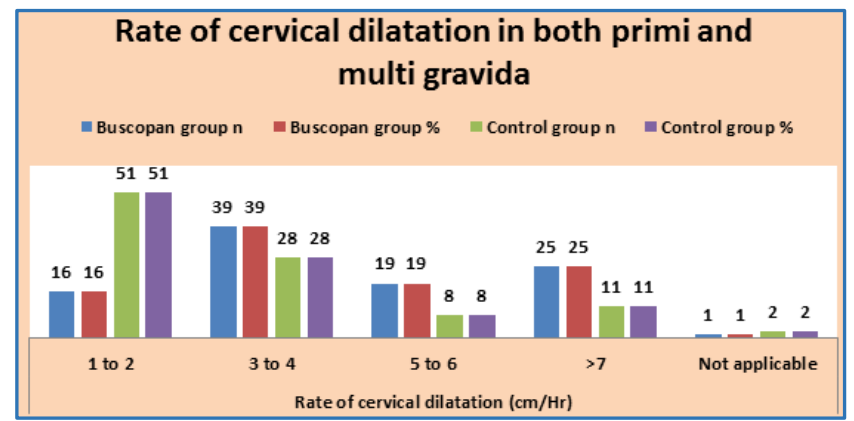

In Buscopan group, a percentage change of pain by $17 \%$ was observed which was statistically significant $(\mathrm{p}<0.001)$. No serious side effects were observed in both the groups. Transient side effects like maternal and foetal tachycardia were observed in few cases. But no adverse effects on the mother and the foetus were observed in these cases.

The mean duration of second stage of labour in Buscopan group was higher than the control group $(9 \pm 4$ minutes vs. $8 \pm 3$ minutes), this difference was not statistically significant ( $p$ $>0.05$ ). Since per vaginal examinations were done once in 4 hours in the study population, the second stage was shorter than anticipated in many cases. The mean duration of third stage of labour in cases and controls was $9 \pm 3.5$ and $9 \pm 3$ minutes respectively. This is statistically not significant ( $p$ $>0.05$ ).

There was no significant difference in the mode of delivery, birth weight, Apgar score and colour of the liquor in both the groups.

\begin{tabular}{|c|c|c|c|c|}
\hline \multirow{2}{*}{$\begin{array}{c}\text { Mode of } \\
\text { Delivery }\end{array}$} & \multicolumn{2}{|c|}{$\begin{array}{c}\text { Buscopan } \\
\text { Group }\end{array}$} & \multicolumn{2}{c|}{$\begin{array}{c}\text { Control } \\
\text { Group }\end{array}$} \\
\cline { 2 - 5 } & $\mathbf{N}$ & $\mathbf{\%}$ & $\mathbf{N}$ & $\%$ \\
\hline $\begin{array}{c}\text { Normal vaginal } \\
\text { delivery }\end{array}$ & 90 & $90 \%$ & 89 & $89 \%$ \\
\hline $\begin{array}{c}\text { Instrumental vaginal } \\
\text { delivery }\end{array}$ & 3 & $3 \%$ & 3 & $3 \%$ \\
\hline LSCS & 7 & $7 \%$ & 8 & $8 \%$ \\
\hline Total & $\mathbf{1 0 0}$ & $\mathbf{1 0 0} \%$ & $\mathbf{1 0 0}$ & $\mathbf{1 0 0} \%$ \\
\hline \multicolumn{4}{|r|}{ Table 1. Mode of Delivery } \\
\hline
\end{tabular}

$\chi^{2}=1.27 \mathrm{df}=3 \mathrm{p}=0.73$ Not significant

\begin{tabular}{|c|c|c|c|c|}
\hline $\begin{array}{c}\text { Indication for } \\
\text { Operative } \\
\text { Interference }\end{array}$ & \multicolumn{2}{|c|}{$\begin{array}{c}\text { Buscopan } \\
\text { Group }\end{array}$} & \multicolumn{2}{c|}{$\begin{array}{c}\text { Control } \\
\text { Group }\end{array}$} \\
\cline { 2 - 5 } & $\mathbf{N}$ & $\mathbf{\%}$ & $\mathbf{N}$ & $\mathbf{\%}$ \\
\hline Cervical dystocia & 1 & $1 \%$ & 3 & $3 \%$ \\
\hline Maternal exhaustion & 1 & $1 \%$ & 3 & $3 \%$ \\
\hline Foetal distress & 3 & $3 \%$ & 2 & $2 \%$ \\
\hline Failure to descent & 5 & $5 \%$ & 3 & $3 \%$ \\
\hline $\begin{array}{c}\text { No operative } \\
\text { interference }\end{array}$ & 90 & $90 \%$ & 89 & $89 \%$ \\
\hline Total & $\mathbf{1 0 0}$ & $\mathbf{1 0 0} \%$ & $\mathbf{1 0 0}$ & $\mathbf{1 0 0 \%}$ \\
\hline \multicolumn{7}{|c|}{ Table 2 } \\
\hline
\end{tabular}

\section{Side Effects}

Maternal tachycardia was observed in one case. Foetal tachycardia was observed in three cases, but there was no variation in the neonatal outcome observed in these cases. Those women who had any side effects like foetal tachycardia in the study group were managed according to labour room protocol of the Institute. The side effects observed were transient.

\section{DISCUSSION}

Modern Obstetricians are now in search of new drugs, which have got the sole beneficiary effect on the dilatation of the internal os with minimal side effects on foetus and the mother. One such antispasmodic drug is Hyoscine butylbromide which has been used to shorten the duration of labour. HBB has been used in obstetric practice for many years.

Several studies, which included both primigravid and multigravid women, have been carried out to evaluate the effect of Buscopan on cervical dilatation. Corsen ${ }^{3}$ (1953) studied the various uses and modes of action of HBB in Obstetrics and found that most prompt action occurred with intravenous and suppository routes. No significant side effects occurred with up to $30 \mathrm{mg}$ dose.

Tiwari $\mathrm{K}$ et $\mathrm{al}^{4}$ (2003) studied the effectiveness of Buscopan and valethamate bromide on cervical dilatation with 300 cases using Buscopan intravenously with $40 \mathrm{mg}$ dose as two divided doses. Significant shortening of the first stage of labour was noted with Buscopan and Valethamate bromide with more marked shortening in Buscopan group. ${ }^{4}$ Sirohiwal, Dahiya and $\mathrm{De}^{5}$ (2005) studied the efficacy of Buscopan rectal suppositories as cervical spasmolytics in labour.

Our study population included 200 patients; of which 100 were controls and remaining 100 were cases. The mean age distribution and period of gestation of our present study was comparable to the other studies. In the present study, both primi and multigravidae are included and the rate of cervical dilatation analysed separately. Majority of the studies had recruited cases for Buscopan at 3-4 cm of cervical dilatation as it indicates the onset of active phase of labour similar to our study.

The mean duration of active phase of labour in study by Gandhi and Sharma et $\mathrm{al}^{9}$ was $144.3 \pm 19.7$ minutes (vs. 288.7 min. in controls) and this was comparable with our study. Kirim SA et $\mathrm{al}^{10}$ in their study reported the mean duration of active phase as $159.3 \pm 40.9 \mathrm{~min}$. (vs. $299 \pm 86 \mathrm{~min}$.).

Comparison of the Duration of Active Phase among Primigravidae in Various studies

\begin{tabular}{|c|c|c|}
\hline Study & $\begin{array}{c}\text { Buscopan } \\
\text { Group (min.) }\end{array}$ & $\begin{array}{c}\text { Control Group } \\
\text { (min.) }\end{array}$ \\
\hline Aggarwal P et al $^{8}$ & 226 & 496 \\
\hline Kirim Set al $^{10}$ & $191.1 \pm 43.06$ & $248.21 \pm 66.16$ \\
\hline Al-Khishali et al $^{11}$ & $167.7 \pm 76.2$ & $193.8 \pm 58$ \\
\hline Samuels LA et al $^{6}$ & 176 & 258 \\
\hline Maria Aziz $^{12}$ & 205 & 263 \\
\hline Al Quahtani et al $^{13}$ & 165 & 215 \\
\hline Makvandi S et al $^{14}$ & $141 \pm 81.7$ & $230 \pm 61.9$ \\
\hline Present study & $114 \pm 75$ & $182 \pm 88$ \\
\hline
\end{tabular}

Comparison of Duration of active Phase among Multigravidae in Various Studies

\begin{tabular}{|c|c|c|}
\hline Study & $\begin{array}{c}\text { Buscopan } \\
\text { Group } \\
\text { (min.) }\end{array}$ & $\begin{array}{c}\text { Control Group } \\
\text { (min.) }\end{array}$ \\
\hline Kirim S et al ${ }^{10}$ & $170.1 \pm 50.87$ & $224 \pm 53.76$ \\
\hline Al-Khishali et al $^{11}$ & $90.1 \pm 37.9$ & $195.6 \pm 72$ \\
\hline Samuels LA et al $^{6}$ & 137 & 200 \\
\hline Maria Aziz $^{12}$ & 106 & 205 \\
\hline Sekhavat L et al 15 & 186 & 260 \\
\hline Present study & $89 \pm 50$ & $113 \pm 40$ \\
\hline
\end{tabular}


All the above studies found that the mean duration of active phase of labour was reduced by Buscopan compared to control group. The reduction in the mean duration of first stage of labour with the use of Buscopan has been found consistently in all these studies. The mean duration of first stage of labour in our study was least compared to the other studies. This is probably because of active management of labour in our study. The difference in the mean duration of active phase of labour between Buscopan and control group in our study was statistically significant.

The rate of cervical dilatation in primigravida in present study is $4.7 \pm 2.2 \mathrm{~cm} /$ hour and $3 \pm 1.9 \mathrm{~cm} /$ hour in Buscopan and control group. Majority of the women ( 41.7 vs. $22 \%$ ) had a rate of cervical dilatation of 3-4 cm/hour.

In study by Makvandi $\mathrm{S}$ et al, 14 the cervical dilatation rate was found to be $2.6 \mathrm{~cm} /$ hour in primi study group \& 1.5 $\mathrm{cm} /$ hour in primi control group. In the study by Maria A, 12 the cervical dilatation rate was $2.04 \mathrm{~cm} /$ hour in primi study group and $1.5 \mathrm{~cm} /$ hour in primi control group. In the Baracho et al ${ }^{16}$ study, the cervical dilatation rates were $1.85 \mathrm{~cm} /$ hour in primi study group and $1.35 \mathrm{~cm} /$ hour in primi control group.

In contrast to our study, Gupta B et al ${ }^{7}$ found that the active phase duration and rate of cervical dilatation in the group that received HBB $(3.9 \pm 2.2$ hours) were not significantly different from the control group (3.6 \pm 2.04 hours). Similar observations were made by Aldahhan $\mathrm{FH}$ et $\mathrm{al}^{2}$ who demonstrated duration of active phase in cases (246 min.) to be significantly longer compared to that in controls (204 min.) which is in contrast to the present study.

The mean duration of second stage of labour in the present study was 9+4 min. and 8+3 min. in Buscopan group and control group respectively. This difference was not statistically significant. Sameuls LA et $\mathrm{al}^{6}$, found the mean duration of second stage labour in Buscopan and control group to be 20 $\mathrm{min}$. and $15 \mathrm{~min}$. respectively with no significant decrease in duration. This is comparable to the present study. In study by Sekhavath et al,15 mean duration of second stage labour in Buscopan group was 20 min. vs. 25.8 min. in control group with no significant decrease. Aldahhan $\mathrm{FH}$ et al, ${ }^{2}$ in their study found the mean duration of second stage labour to be $15.6 \mathrm{~min}$. and $12.7 \mathrm{~min}$. in Buscopan and control group respectively, thus showing no decrease of duration.

In the present study, a mean percentage change in pain score of $17 \%$ was observed in Buscopan group which is comparable with that observed in study by Aggarwal et $\mathrm{al}^{7}$. However, a percentage change in pain of $12 \%$ was observed in control group also which may be explained as pain being a subjective component and many factors like personal pain threshold, pre-existing psychological problems and kind of support affect its assessment. Aggarwal et $\mathrm{al}^{8}{ }^{8}$ in their study showed a percentage change of pain in Buscopan group by $35.6 \%$ in comparison with their control group decrease of pain by $12.5 \%$. This study has used the visual analogue scale and calculated the percentage decrease of pain as in the present study. In a study by Fardiazar $\mathrm{Z}$ et al, ${ }^{17}$ the need for analgesic has decreased by $20 \%$ in Buscopan group compared to the control group.

\section{CONCLUSION}

Acceleration of labour is considered to be an important factor in reducing maternal morbidity as well as neonatal complications. Various forms of pharmacological intervention have helped in shortening the duration of labour by augmenting cervical dilatation making child birth safe. One such drug is Buscopan, which by its spasmolytic action helps in cervical dilatation and additionally considered to decrease pain.

\section{The following Conclusions were drawn from the study}

1. Buscopan is effective in reducing the duration of active phase of labour especially in primigravidae.

2. There is significant improvement in the rate of cervical dilatation with administration of Buscopan in both primi and multigravidae.

3. Buscopan also has significant effect on reducing the pain in labour.

4. There is no significant variation in the duration of second and third stage of labour with use of Buscopan.

5. Transient side effects like foetal tachycardia observed in few women due to Buscopan but with no untoward effect on the mother or the newborn. There is no difference in the mode of delivery with use of Buscopan.

Thus, effective shortening of the duration of labour and pain relief can be achieved without any significant detrimental effects on the mother or the foetus. Hence, it can be better recommended for use in modern obstetrics to relieve spasm and to hasten the rate of cervical dilatation.

\section{Limitations of the Study}

1. Since this study was not a double blinded study and without randomisation subjective variation in the observations noted may be present.

2. Assessing subjective component like pain is not always accurate as it is influenced by many confounding factors like personal pain threshold, psychological factors and socioeconomic status.

3. The period of study is short, hence many outcomes like longterm neurodevelopmental outcomes and maternal side effects may not have surfaced.

Hence, well-designed randomised double blind control studies are recommended further for improving level of evidence.

\section{REFERENCES}

1. Gelber S, Sciscione A. Mechanical method of cervical ripening and labor induction. Clinical Obstetrics and Gynaecology 2006;49(3):642-57.

2. Aldahhan FH, Alwaeely FA, Raheem F. Evaluation of the effect of Buscopan (HYOSCINE-N-BUTYLBROMIDE) on the duration of labour. Bas J Surg 2011;17:25-9.

3. Corsen G. A study of the use and mode of action of the antispasmodic drug Buscopan in gynecology and obstetrics. Med Klin 1953;48:2186-8.

4. Tiwari K, Jabeen R, Sabzposh NA, et al. Comparison of hyoscine-N-butylbromide and valethamate bromide in shortening the duration of labor. Ind Med Gaz 2003;137:15-9.

5. Sirohiwal D, Dahiya K, Mandira DE. Efficacy of hyoscine butylbromide (Buscopan) suppositories as cervical spasmolytic agent in labor. Australian and New Zealand Journal of Obstet and Gynaecol 2005;45(2):128-9. 


\section{Jemds.com}

6. Sameuls LA, Christie L, Roberts-Gittens B, et al. The effect of hyoscine butylbromide on the first stage of labour in term pregnancies. BJOG 2007;114(12):1542-6.

7. Gupta B, Nellore V, Mittal S. Drotaverine hydrochloride vs. hyoscine- $\mathrm{N}$ butyl bromide in augmentation of labour. Int $\mathrm{J}$ Gynaecol Obstet 2008;100(3):244-7.

8. Aggarwal P, Zutshi V, Batra S. Role of hyoscine Nbutylbromide (HBB, Buscopan) as labor analgesic. Indian J Med Sci 2008;62(5):179-84.

9. Gandhi M, Sharma J. Comparative study of intravenous drotaverine and rectal hyoscine for augmentation of labour. IJRRMS 2014;4(3):1-5.

10. Kirim S, Asicioglu O, Yenigul N, et al. Effect of intravenous hyoscine-N-butylbromide on active phase of labor progress: a randomized double blind placebo controlled trial. J Matern Foetal Neonatal Med 2015;28(9):1038-42.

11. Al-Khisali WAH, Rasheed FA, Hussain SA. Effect of Hyoscine butyl bromide on normal labour in primi and multi gravida women. J Adv Sci Res 2012;3(4):70-3.

12. Aziz M. Effect of rectal hyoscine butyl bromide suppositories on first stage of labour. International Journal of Advanced Research 2014;2(4):128-35.

\section{Original Research Article}

13. Al Qahtani NH, Hajeri FA. The effect of hyoscine butyl bromide in shortening the first stage of labor: a double blind, randomized, controlled, clinical trial. Ther Clin Risk Manag 2011;7:495-500.

14. Makvandi S, Tadayon M, Abbaspour M. Effect of hyoscine$\mathrm{N}$-butyl bromide rectal suppository on labor progress in primigravid women: randomized double-blind placebocontrolled clinical trial. Croat Med J 2011;52(2):159-63.

15. Sekhavat L, Karbasi SA, Fallah R, et al. Effect of hyoscine butyl bromide first stage of labour in multiparous women. Afr Health Sci 2012;12(4):408-11.

16. Baracho HM, Kamat JR, Kunakalekar K, et al. Hyoscine N butyl bromide in acceleration of labour. J Obstet and Gynaecol Ind 1984;34(3):510-3.

17. Fardiazar Z, Niknami F, Mashyaekhi S, et al. Hyoscine-Nbutylbromide versus atropine as labour accelerant and analgesic: a randomized clinical trial. Pak J Biol sci 2013;16(9):443-5. 